\title{
Isolation and characterization of Macrophomina phaseolina isolates prevailing in Sindh, Pakistan
}

Khadim Hussain Wagan ${ }^{1 *}$, Muhammad Ibrahim Khaskheli ${ }^{2}$, Jamal-UDdin Hajano ${ }^{1}$ and Abdul Ghani Lanjar ${ }^{2}$

1. Department of Plant Pathology, Sindh Agriculture University, Tandojam70060-Pakistan

2. Department of Plant Protection, Sindh Agriculture University, Tandojam 70060-Pakistan

*Corresponding author's email: khwagan@hotmail.com

Citation

Khadim Hussain Wagan, Muhammad Ibrahim Khaskheli, Jamal-U-Ddin Hajano and Abdul Ghani Lanjar. Isolation and characterization of Macrophomina phaseolina isolates prevailing in Sindh, Pakistan. Pure and Applied Biology. Vol. 7, Issue 4, pp 1309-1315. http://dx.doi.org/10.19045/bspab.2018.700152

Received: 05/07/2018

Revised: $24 / 08 / 2018$

Accepted: 02/09/2018

Online First: 07/09/2018

\section{Abstract}

Macrophomina phaseolina (Tassi) Goid is economically important fungal pathogen with wide host range. In this study we found morphological and phenotypical variation among isolates of the fungus infecting sunflower crop in Sindh province of Pakistan. Thirty two M. phaseolina isolates were obtained from infected plant samples of sunflower collected from different ten districts viz., Badin, Thatta, Hyderabad, Tando Muhammad Khan, Shaheed Benazirabad, Mirpurkhas, Sanghar, Dadu, Sukkur and Khairpur. Significant variation in characteristics was noticed among collected isolates. They were usually black, blackish-gray, grayish-black and gray in colony color. Generally three growths pattern; dense, feathery and restricted were seem. Among them dense was most common $(50.0 \%)$ followed by feathery $(34.36 \%)$ and restricted (15.64\%). Maximum colony growth $(90.0 \%)$ and minimum $(65.0 \%)$ was recorded after 7 days of inoculation on medium. Feathery growth was generally fast and restricted growth was slow. Maximum average linear colony growth $(13 \mathrm{~mm})$ and minimum $(9 \mathrm{~mm})$ growth was noted. Isolates showed significantly varied sizes of microsclerotia. Maximum sclerotia size $(124.0 \mu \mathrm{m})$ was obtained from fields of Badin while, minimum size of microsclerotia $(83.0 \mu \mathrm{m})$ from sunflower fields of Sukkur. Microsclerotia from dense growth pattern were black and big in size and small microsclerotia from gray growth pattern.

Keywords: Charcoal rot; Isolates and Characterization; Macrophomina phaseolina; Sunflower

Introduction

Macrophomina phaseolina (Tassi) Goid. which is dominant fungal pathogen of sunflower and is polyphagous causing disease to many other crop species. Importance of $M$. phaseolina rot is increasing with time because of attack on root, stem and fruit of more than 500 plant species worldwide, especially in regions where temperature is high $[1,2]$. Up to $90 \%$ losses due to this fungus are reported in sunflower under favorable conditions for infection [3]. The fungus belongs to Phylum: Ascomycota, class: Botryosphaeriales, order: Botryosphaeriales and family: Botryosphaeriaceae. M. phaseolina isolates 
are differing in various morphological and other aspects like mycelium colour, microsclerotia distribution, pycnidia formation and chlorate phenotypes [4]. Iqbal and Mukhtar [5] reported 65 isolates of $M$. phaseolina from Punjab and Khyber Pakhtunkhwa (KPK) provinces of Pakistan which are varying in morphological characteristics and pathogenic nature to infect mungbeen crop. Ashraf et al. [6] conducted such study in Punjab province to differentiate morphologically and virulent potential of 24 isolates of this fungus from maize crop which are significantly changed in the geographic regions. Furthermore, morphological and virulent variation among isolates of $M$. phaseolina collected from mash is examined by Riaz et al. [7]. Better understanding variability within pathogen population for traits, survival and fitness in different agro-ecological regions, definitely may support in design improved management strategies [8]. Hence, this study was planned to characterize $M$. phaseolina isolates prevailing in sunflower fields of Sindh province of Pakistan.

\section{Materials and methods}

\section{Collection of samples}

Plant samples showing charcoal rot symptoms and soil samples near root zone of infected plants were collected from various farmer's fields and research stations at sunflower growing districts of Sindh. All samples were brought to the laboratory for further studies.

\section{Isolation and identification of Macrophomina phaseolina isolates Plant sample}

After surface washing of plant samples under tap water; small pieces $(0.5 \mathrm{~cm})$ from symptomatic stem and roots were cut and disinfected with $1 \%$ sodium hypochlorite for 2 minutes and then rinsed three times in sterilized distilled water. Infected small pieces were placed on Petri plates (5pieces per plate) containing potato dextrose agar
(PDA) medium. All Petri plates were incubated at $30{ }^{\circ} \mathrm{C}$ for 7 days. Further, pure culture of the fungus was maintained by hyphal tip method. Isolates of M. phaseolina were named in abbreviate along with host plant and where numbered in numerical digits starting from 1 to 32 .

\section{Morphological characterization of Macrophomina phaseolina isolates Colony growth}

To calculate growth rate of isolates, $5 \mathrm{~mm}$ disc from active growth of fungus was taken and placed at center of $90 \mathrm{~mm}$ diameter Petri plate containing sterilized PDA medium. All Petri plates were incubated at $30{ }^{\circ} \mathrm{C}$ for 7 days. Each treatment was replicated five times. Observation on growth speed was taken by measuring diameter of Petri plates in mm per day and at the time of experimental termination. Furthermore observations on colony color and growth pattern were recorded for each isolates.

\section{Sclerotia size}

Slides were prepared from 7 days old pure culture of each isolates and examined under microscope ocular micrometer. Length and width of ten randomly selected sclerotia was measured in $\mu \mathrm{m}$ and were presented as average of both dimension. Additionally shape of sclerotium was noticed for each isolate.

\section{Statistical analysis}

Data regarding radial growth, average growth $(\mathrm{mm} /$ day $)$ and sclerotia size $(\mu \mathrm{m})$ was statistically analysis for determining LSD at $\alpha=0.005$ using STATISTIX v. 8.1 software (Analytical Software).

\section{Results}

Remarkable variation in morphological and phenotypical characteristics was noticed in purified cultures of $M$. phaseolina. Thirty two $M$. phaseolina isolates were obtained from infected plant samples of sunflower collected from different ten districts of Sindh (Table $1 \&$ Figure 1). They were usually black, blackish-gray, grayish-black and gray 
in colony color (Table 2). Generally three growth patterns; dense, feathery and restricted were seen (Table 2). Among them dense was most common $(50.0 \%)$ followed by feathery (34.36\%) and restricted (15.64\%) (Table 2). Maximum colony growth $(90.0 \%)$ and minimum (65.0\%) was recorded after 7 days of inoculation on PDA medium. Feathery growth was generally faster than restricted type growth (Table 2). Average linear colony growth per/day ranged from 9$13 \mathrm{~mm}$, which significantly differ with each other (Table 2). Sclerotium size also significantly varied among the isolates. Isolates showed significantly varied sizes of microsclerotia. MPS16 isolate collected from fields of Badin showed maximum sclerotium size $(124.0 \mu \mathrm{m})$ while, minimum size of sclerotium $(83.0 \mu \mathrm{m})$ was measured in MPS29 obtained from sunflower fields of Sukkur (Table 2). Microsclerotia from dense growth pattern were black and big in size and small microsclerotia from gray growth pattern.

Table 1. Isolates of Macrophomina phaseolina obtained from different sunflower farmer's fields of Sindh

\begin{tabular}{|c|c|}
\hline District & Isolates \\
\hline Badin & MPS12, MPS13, MPS14, MPS15, MPS16, MPS17 \\
Thatta & MPS18, MPS19, MPS20 \\
Hyderabad & MPS1, MPS2, MPS3, MPS4, MPS5 \\
Tando Muhammad Khan & MPS9, MPS10, MPS11 \\
Shaheed Benazirabad & MPS21, MPS22, MPS23 \\
Mirpurkhas & MPS6, MPS7, MPS8 \\
Sanghar & MPS24, MPS25, MPS26 \\
Dadu & MPS31, MPS32 \\
Sukkur & MPS29, MPS30 \\
Khairpur & MPS27, MPS28 \\
\hline
\end{tabular}

\section{Discussion}

Collected cultures of $M$. phaseolina significantly varied in growth pattern, colour frequency and shape as well size. Thirty two isolates were obtained from infected plant samples of sunflower collected from different ten districts of Sindh, during this study. They were usually black, blackish-gray, grayishblack and gray in colony color. Generally three growth patterns; dense, feathery and restricted were seem. Among them dense was most common $(50.0 \%)$ followed by feathery $(34.36 \%)$ and restricted (15.64\%). Maximum colony growth $(90.0 \%)$ and minimum $(65.0 \%)$ was recorded after 7 days of inoculation on medium. Feathery growth was generally fast and restricted growth was slow. Saleh et al. [9] and Atiq et al. [10] also reported three types of colony growth (dense, feathery and restricted) patterns of $M$. phaseolina isolates when grown on media. Aboshosha, et al. [11] also reported similar findings about growth pattern of $M$. phaseolina.

Maximum average linear colony growth per day $(13 \mathrm{~mm})$ and minimum $(9 \mathrm{~mm})$ growth was noted. Isolates showed significantly varied sizes of microsclerotia. Karunanithi et al. [12] described cultural and pathogenic variation of isolates of $M$. phaseolina into three groups. Isolates were significantly varied in ability to produce sclerotia. Maximum mycelial growth $(90 \mathrm{~mm})$ on PDA was recorded by $\mathrm{I}_{14}$ and the minimum by $\mathrm{I}_{3}$ (72.5 mm). Linhai, et al. [13] observed rich variations in morphological characteristics, including density of aerial mycelia, sclerotia quantity, sclerotium size and growth speed of colony of $M$. phaseolina. 
Maximum sclerotia size $(124.0 \mu \mathrm{m})$ was obtained from fields of Badin while, minimum size of microsclerotia $(83.0 \mu \mathrm{m})$ from sunflower fields of Sukkur. Microsclerotia from dense growth pattern were black and big in size and small microsclerotia from gray growth pattern. Suriachandraselvan and Seetharaman [14] reported that the most virulent isolate (MP8)

\section{Table 2. Morphological characteristics of} Table 2. Morphological char
different districts of Sindh

\begin{tabular}{|c|c|c|c|c|c|c|}
\hline Isolate & $\begin{array}{l}\text { Colony } \\
\text { color }\end{array}$ & $\begin{array}{l}\text { Growth } \\
\text { pattern }\end{array}$ & $\begin{array}{c}\text { Radial growth } \\
(\mathbf{m m})\end{array}$ & $\begin{array}{c}\text { Average growth } \\
\text { (mm/day) }\end{array}$ & $\begin{array}{l}\text { Sclerotia } \\
\text { size }(\mu \mathrm{m})\end{array}$ & $\begin{array}{c}\text { Sclerotia } \\
\text { shape }\end{array}$ \\
\hline MPS1 & Black & Dense & $90 \mathrm{a}$ & $13 a$ & $112 j$ & Ovoid \\
\hline MPS2 & Blackish-gray & Feathery & $90 \mathrm{a}$ & $13 a$ & $107 \mathrm{~m}$ & Irregular \\
\hline MPS3 & Black & Dense & $87 d$ & $12 \mathrm{ab}$ & $114 \mathrm{~h}$ & Ovoid \\
\hline MPS4 & Blackish-gray & Dense & $88 \mathrm{c}$ & $13 \mathrm{ab}$ & $113 i$ & Ovoid \\
\hline MPS5 & Black & Dense & $89 \mathrm{~b}$ & $13 \mathrm{ab}$ & $117 \mathrm{e}$ & Round \\
\hline MPS6 & Grayish-black & Feathery & $90 \mathrm{a}$ & $13 a$ & $99 p$ & Round \\
\hline MPS7 & Gray & Restricted & $71 \mathrm{f}$ & $10 \mathrm{c}$ & $90 \mathrm{t}$ & Ovoid \\
\hline MPS8 & Grayish-black & Feathery & $87 d$ & $12 \mathrm{ab}$ & $100 \mathrm{o}$ & Irregular \\
\hline MPS9 & Blackish-gray & Feathery & $90 \mathrm{a}$ & $13 a$ & 1081 & Oblong \\
\hline MPS10 & Black & Dense & $89 \mathrm{~b}$ & $13 \mathrm{ab}$ & $114 \mathrm{~h}$ & Ovoid \\
\hline MPS11 & Black & Dense & $89.2 \mathrm{ab}$ & $13 a b$ & $115 \mathrm{~g}$ & Ovoid \\
\hline MPS12 & Black & Dense & $90 \mathrm{a}$ & $13 a$ & $120 \mathrm{c}$ & Ovoid \\
\hline MPS13 & Black & Dense & $88 \mathrm{c}$ & $13 \mathrm{ab}$ & $118 \mathrm{~d}$ & Round \\
\hline MPS14 & Black & Dense & $90 \mathrm{a}$ & $13 a$ & $117 \mathrm{e}$ & Ovoid \\
\hline MPS15 & Blackish-gray & Dense & $87 d$ & $12 \mathrm{ab}$ & $122 b$ & Ovoid \\
\hline MPS16 & Black & Dense & $90 \mathrm{a}$ & $13 a$ & $124 \mathrm{a}$ & Ovoid \\
\hline MPS17 & Black & Dense & $90 \mathrm{a}$ & $13 \mathrm{a}$ & $116 \mathrm{f}$ & Round \\
\hline MPS18 & Black & Dense & $87 d$ & $12 \mathrm{ab}$ & $118 \mathrm{~d}$ & Ovoid \\
\hline MPS19 & Blackish-gray & Dense & $86 \mathrm{e}$ & $12 b$ & $113 \mathrm{i}$ & Ovoid \\
\hline MPS20 & Blackish-gray & Feathery & $90 \mathrm{a}$ & $13 \mathrm{a}$ & $107 \mathrm{~m}$ & Ovoid \\
\hline MPS21 & Grayish-black & Feathery & $90 \mathrm{a}$ & $13 a$ & $92 \mathrm{~s}$ & Oblong \\
\hline MPS22 & Grayish-black & Feathery & $90 \mathrm{a}$ & $13 a$ & $95 q$ & Irregular \\
\hline MPS23 & Grayish-black & Feathery & $89 \mathrm{~b}$ & $13 \mathrm{ab}$ & $100 \mathrm{o}$ & Oblong \\
\hline MPS24 & Grayish-black & Dense & $67 i$ & 10de & $95 q$ & Round \\
\hline MPS25 & Grayish-black & Feathery & $90 \mathrm{a}$ & $13 \mathrm{a}$ & $93 \mathrm{r}$ & Oblong \\
\hline MPS26 & Grayish-black & Feathery & $88 \mathrm{c}$ & $13 \mathrm{ab}$ & $88 \mathrm{v}$ & Irregular \\
\hline MPS27 & Grayish-black & Restricted & $65 j$ & $9 \mathrm{e}$ & $90 \mathrm{t}$ & Round \\
\hline MPS28 & Gray & Restricted & $70 \mathrm{~g}$ & $10 \mathrm{~cd}$ & $86 w$ & Round \\
\hline MPS29 & Gray & Restricted & $69 \mathrm{~h}$ & $10 \mathrm{~cd}$ & $83 x$ & Round \\
\hline MPS30 & Grayish-black & Restricted & $71 \mathrm{f}$ & $10 \mathrm{c}$ & $89 u$ & Round \\
\hline MPS31 & Blackish-gray & Dense & $86 \mathrm{e}$ & $12 b$ & $110 \mathrm{k}$ & Ovoid \\
\hline MPS32 & Grayish-black & Feathery & $88 \mathrm{c}$ & $13 \mathrm{ab}$ & $104 n$ & Irregular \\
\hline $\begin{array}{c}\text { LSD } \\
(\mathrm{alfa}=0.5)\end{array}$ & & & $0.9021 \pm 0.456$ & $0.4343 \pm 0.2202$ & $\begin{array}{c}0.799 \pm 0.4 \\
06\end{array}$ & \\
\hline
\end{tabular}

Sclerotia size $=$ length + width $/ 2$ produced highest mycelial growth $(87.1 \mathrm{~mm})$ and abundant sclerotia in all the media within $48.8 \mathrm{~h}$. while, Bradley and Rio [15] isolated black microsclerotia (76 \pm 28 micro $\mathrm{m}$ in diameter) from vascular tissues of lower stems. The fungus was confirmed on the basis of colony colour, morphology and size of microsclerotia. 


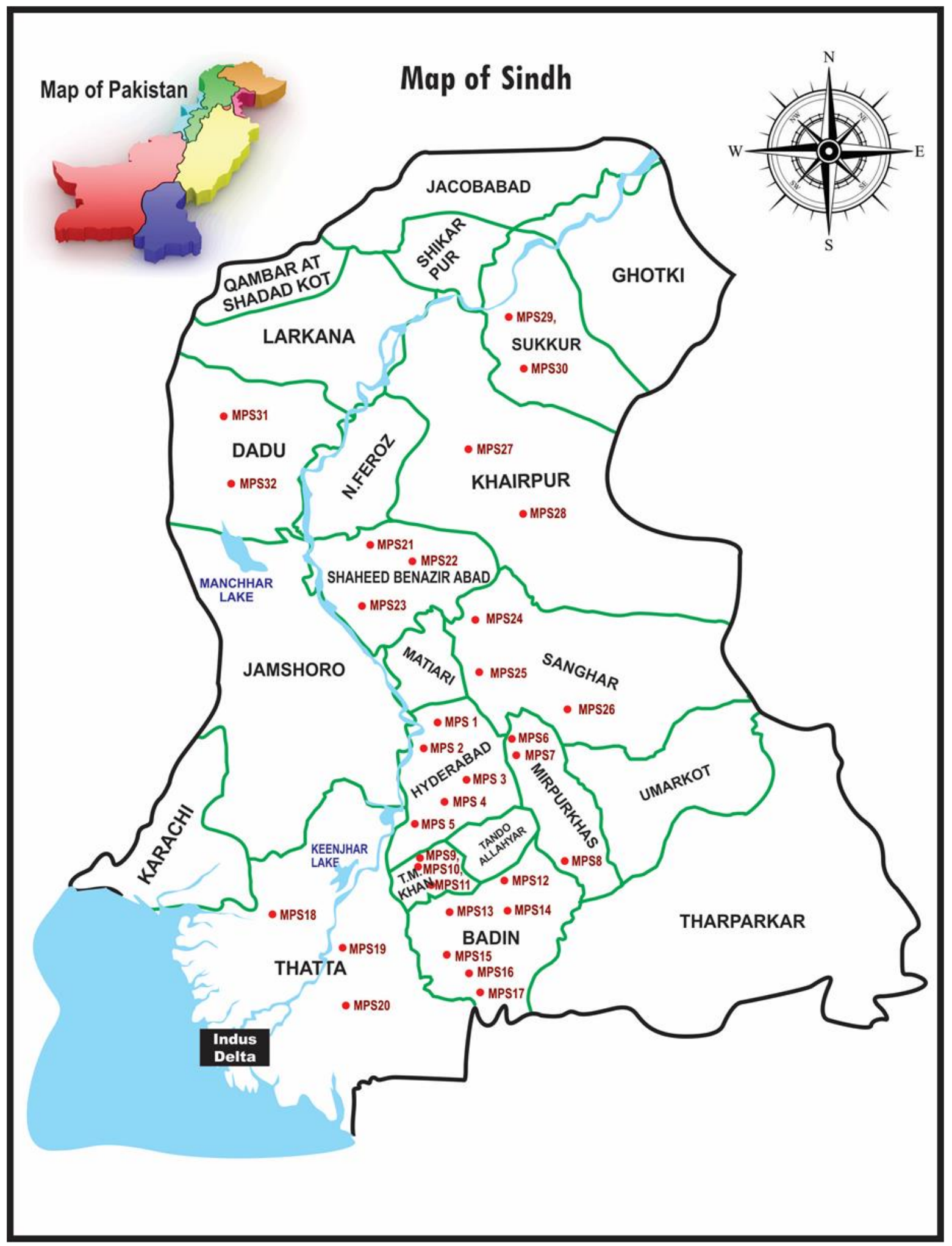

Figure 1. Prevlance of different Macrophomina phaseolina isolates in different districts of Sindh, Pakistan 


\section{Conclusion}

Remarkable variation in morphological and phenotypical characteristics was noticed in purified cultures of $M$. phaseolina. Thirty two M. phaseolina isolates were obtained from infected plant samples of sunflower collected from ten different districts of Sindh. They were usually black, blackish-gray, grayish-black and gray in colony color. Generally three growth patterns; dense, feathery and restricted were seen and among them dense was most common. MPS16 isolate collected from fields of Badin showed maximum sclerotium size.

\section{Authors' contributions}

Conceived and designed the experiments: KH Wagan \& MI Khaskheli, Performed the experiments: KH Wagan, Analyzed the data: J Hajano \& AG Lanjar, Contributed reagents/ materials/ analysis tools: KH Wagan \& J Hajano, Wrote the paper: KH Wagan.

\section{References}

1. Viana FMP \& de Souza NL (2002). Effect of temperature, water tension interaction on germination of Macrophomina phaseolina microsclerotia. Fitopato Bras 27(3): 268-272.

2. Gupta GK, Sharma SK \& Ramteke R (2012). Biology, epidemiology and management of the pathogenic fungus Macrophomina phaseolina (Tassi) Giod with special reference to charcoal rot of soybean (Glycine $\max (\mathrm{L}$.$) ) Merril. J$ Phytopathol 160: 167-180.

3. Khan SN (2007). Macrophomina phaseolina as causal agent for charcoal rot of sunflower. Mycopath 5(2): 111118.

4. Almomani F, Alhawatema $\mathrm{M} \&$ Hameed K (2013). Detection, identification and morphological characteristic of Macrophomina phaseolina: the charcoal rot disease pathogens isolated from infected plants in Northern Jordan. Arch
Phytopathol Plant Prot 46(9): 10051014.

5. Iqbal U \& Mukhtar T (2014). Morphological and pathogenic variability among Macrophomina phaseolina isolates with mungbean (Vigna radiata) Wilczek from Pakistan. Sci World J 2014: 1-9. http://dx.doi.org/10.1155/2014/950175.

6. Ashraf W, Sahi ST, Haq I \& Ahmed S (2015). Morphological and pathogenic variability among Macrophomina phaseolina isolates associated with maize (Zea mays) in Punjab-Pakistan. Int J Agric Biol 17: 1037-1042.

7. Riaz A, Khan SH, Iqbal SM \& Shoaib M (2007). Pathogenic variability among Macrophomina phaseolina (Tassi) Goid, isolates and identification of sources of resistance in mash against charcoal rot. Pak J Phytopathol 19(1): 44-46.

8. Kaur S, Dhillon GS, Brar SK, Vallad GE, Chand R \& Chauhan VB (2012). Emerging phytopathogen Macrophomina phaseolina: biology, economic importance and current diagnostic trends. Crit Rev Microbiol 38(2): 136-151

9. Saleh AA, Ahmed HU, Todd TC, Travers SE, Zeller KA, Leslie JF \& Garrett KA (2010). Relatedness of Macrophomina phaseolina isolates from tall grass prairie, maize, soybean and sorghum. Mol Ecol 19: 79-91

10. Atiq M, Shabeer A \& Ahmed I (2001). Pathogenic and cultural variations in Macrophomina phaseolina, the cause of charcoal rot in sunflower. Sarhad J Agri 17(2): 253-255.

11. Aboshosha SS, Atta Alla SI, El-korany AE \& El-Argawy E (2007). Characterization of Macrophomina phaseolina isolates affecting sunflower growth in El-Behera Governorate, Egypt. Int J Agri \& Bio 9(6): 807-815. 
12. Karunanithi K, Muthusamy M \& Seetharaman K (1999). Cultural and pathogenic variability among the isolates of Macrophomina phaseolina causing root rot of Sesamum. Pl Dis Res 14(2): 113-117.

13. Linhai W, Yanxin Z, Donghua Li, Junbin $\mathrm{H}$, Wenliang Wei, Lv Haixia \& Xiurong $\mathrm{Z}$ (2011). Variations in the isolates of Macrophomina phaseolina from sesame in China based on amplified fragment length polymorphism (AFLP) and pathogenicity. Afr J Microbiol Res 5(31): 5584-5590.

14. Suriachandraselvan $M \&$ Seetharaman $K$ (2003). Effect of culture media on growth and sclerotial production of different isolates of Macrophomina phaseolina infecting sunflower. J Mycol Pl Pathol 33(2): 226-229.

15. Bradley CA \& Rio LED (2003). First report of charcoal rot on soybean caused by Macrophomina phaseolina in North Dakota. Pl Dis 87(5): 601. 